\section{Travel Grants for 2000 Annual Meeting Doubled}

APSA has doubled the number of travel grants for advanced graduate students attending the Annual Meeting. Funded through the generosity of APSA members, the maximum award for any grant is $\$ 300$ and must be used for travel to this year's meeting in Washington, DC. Grants will be awarded in two categories: international graduate students attending U.S. institutions and advanced American graduate students presenting a paper or poster listed in the 2000 Program.

Interested students must complete a short application and submit a letter of support prepared by their department chair, graduate advisor, or graduate studies director. Applications submitted without an accompanying a letter of support will not be considered; these letters are used to make distinctions among candidates. Applicants who are furthest along in their course of study will be given greatest consideration. Previous grant recipients are not eligible.

Applications and further details are available on the APSA web site at www.apsanet.org/mtgs. Questions should be directed to Brigette Blue at bblue@apsanet.org. The deadline for receipt of completed applications is July 7, 2000.

\section{APSA-AAPC Roundtable Set for Annual Meeting}

APSA and the American Association of Political Consultants (AAPC) recently established a cooperative relationship and have agreed to cosponsor a roundtable on political advertising at the 2000 Annual Meeting in Washington, DC.

Darrell West, Brown University; Bill Hamilton, Hamilton, Beattie \& Staff; Phil Noble, Phil Noble Associates; Gary Nordlinger, Nordlinger Associates; and Ray Strother, Strother/Duffy/Strother will participate in "The Best Campaign Ads of the 2000 Elections: Winners of the AAPC Poly Awards," during which they will view the award-winning advertisements and offer commentary on each.

\title{
2000 Meeting to Feature E-Jobs, A Virtual Placement Service
}

Building on the success of the online job placement service

at the 1999

meeting in

Atlanta,

APSA will again open the E-Jobs service in mid-June for the 2000

Annual

Meeting. Employers

and job candidates wishing to take part in the Placement Service will be able to submit their information via a specifically designed web site at www.apsanet.org. The Placement Service will operate as usual during the meeting - beginning Thursday, August 31, and running through mid-morning, Sunday, September 3-but for the second year, both employers and candidates will be able to learn about and communicate with each other before traveling to the meeting.

\section{What is E-Jobs?}

The E-Jobs system provides registered job candidates access to a searchable database of job openings. Employers who have registered for the service can review candidates' applications and resumes before the meeting. The primary benefit of this service is that placement participants will no longer need to spend long hours onsite reviewing binders of job listings or job candidates. Employers and candidates may contact each other throughout the summer to arrange interviews, allowing both parties to arrive in Washington with a plan.

\section{How Does It Work?}

\section{Registration Submission}

Employers and job candidates wishing to participate in the Place- ment Service during the 2000 Annual Meeting must submit the appropriate online registration forms via the E-Jobs site. Employers are asked to submit all relevant information regarding available jobs (including starting date, appointment range, and areas of specialty) and to indicate whether a representative will be on site to interview during the meeting. Employers may also reserve an interview table in advance. Employers whose departments are not members of the Association's Departmental Services Program will be charged $\$ 100$ to participate in the service. Job candidates are asked to complete a brief form that requests details about their education, training, professional experience, special skills, and type of position desired and to voluntarily upload a copy of their resume. Candidates must also indicate if they plan to attend the meeting in Washington. The service is free to candidates who are register for the meeting and complete the online Placement registration form.

Both the employer and job candidate forms will be available online by mid-June. Interested participants must register by August 25. Upon completing the appropriate form, each user will receive a unique ID number and password. Each form submitted will be reviewed by APSA and posted to the E-Jobs web site. Both candidates and employers may use their ID and password at any time to enter the system to edit their submission or search the appropriate database.

\section{Searching the Database}

With the exception of having access to their own listings, employers will only be allowed to enter the candidate database. Similarly, job candidates will only be able to fully access 
the job database. The 2000 E-Jobs search engine has been enhanced to allow registrants to search by eight general categories and to do a simple keyword search. If an employer is seeking a candidate with training in a specific subfield they will now have the opportunity to search across over 90 different identified areas of expertise. Also new for 2000 will be the ability to sort items in the database by date of submission, thereby identifying the jobs or candidates that have been added most recently.

\section{Onsite in Washington}

During the Annual Meeting, a limited number of computer terminals will be available in the onsite Placement area for both candidates and employers to search the E-Jobs database. Job listings may be accepted from employers onsite if they are submitted in person with a 3.5" IBM disk containing all relevant information. All CANDIDATES MUST PREREGISTER for the meeting online before arriving in Washington.

For the first time, APSA will provide no binders containing job or candidate information at the meeting. Candidates and employers are highly encouraged to consult the E-Jobs database in preparation for arrival in Washington.

To help facilitate communication between candidates and employers, the Placement Service will introduce an electronic messaging service that will operate as part of the general message service for the meeting. Placement participants may communicate with each other by using this system. Several messaging computers will be available in the Placement area and will be accessible from the other two meeting hotels. Only registered Annual Meeting attendees will be listed on the message service. All placement participants must be registered for the Annual Meeting.

We anticipate the 2000 E-Jobs service will be a great success. In 1999 candidates and employers enthusiastically embraced the new system. A record 944 job seekers registered online and nearly 100 employers submitted jobs online, allowing candidates to review nearly 150 job openings throughout the summer of 1999.

If you have any questions regarding E-Jobs, you can visit the online site at www.apsanet.org/jobsplc/ placement or you can email placement coordinator Joyce Williams at placement@apsanet.org.

\section{APSA to Launch Resume Database}

APSA members in search of employment will have a new tool to assist them this fall, the APSA Resume Database. Job seekers will be able to submit their resumes to an online database for review by potential employers. The system builds upon the job candidate portion of the online

Placement Service, E-Jobs.

Users will complete a brief submission form that seeks details on their education, research interests, primary fields of study, and areas of specialization. Additionally, users will also be able upload a copy of their resume/curriculum vitae or provide a link to an online version.

Employers who are members of the APSA's Departmental Services Program will have access to the database. Employers will be able to search on any of the categories listed above or they can do a simple keyword search.

Users of the Resume Database will be provided a unique username and password that will allow them access to their information. Users may update their listing at any time once they have logged on.

For more information about the upcoming service, visit APSAnet at http://www.apsanet.org.

\section{APSA to Offer Improved PSNonline}

Subscribers to the Personnel Service Newsletter and PSNonline will find a newly enhanced system in place when they $\log$ on in mid-June. To better assist subscribers in locating the jobs that interest them, APSA has developed a more user-friendly interface and improved the site's search engine.

The greatest benefit of the new system will be the flexibility in searching. Subscribers will now be able to sort jobs by geographical preference, as well as position title, starting date, primary field, subfield(s), and institution type. When searching subfields, users may select from over 90 categories, ranging from international political economy to political parties and organizations. Other new features of PSNonline include a quick link to all jobs submitted in the previous 48 hours, keyword or key phrase searching across the job database, and a special section for positions in an applied setting, such as think tanks and government agencies.

APSA is also working to simplify the job submission process. Employers will soon be able to use a single web-based form to submit job listings for both the Personnel Service Newsletter and the Annual Meeting Placement Service. Once the new forms are available, all employers will be required to submit job listings for $P S N$ via the online system. APSA will no longer accept listings emailed or faxed to the national office.

Access to the Newsletter will remain subscription-based and subscribers must be APSA members. Subscriptions are available for $\$ 40$ (print copy and online access) and $\$ 20$ (online access only). 